\title{
Discurso del Coordinador Principal del Centro de Investigación Científica CINC-ANSP en la presentación pública del quinto número de la revista "Policía y Seguridad Pública"
}

Señor Subdirector Ejecutivo de la Academia Nacional de Seguridad Pública, Comisionado José Manuel Olivares Rivera y autoridades que nos acompañan en mesa de honor, invitados especiales, damas y caballeros tengan todos muy buenos días.

Los problemas de seguridad y violencia en El Salvador requieren de aportes fundamentales, medidas audaces y trascendentales, compromisos fuertes y firmes de la nación entera, acción de los buenos ciudadanos y soluciones próximas a lo definitivo y contundente; creyendo que el futuro puede ser mejor y que habrá por lo tanto esperanza. Estos imperativos conciernen a la restauración de la paz social y el orden público que son aspiraciones legítimas y justas de todo pueblo, permítaseme citar una porción del Antiguo Testamento. Comienza la cita, abro comillas "Toda la tierra está en reposo y en paz; se cantaron alabanzas. Aún los cipreses se regocijaron a causa de ti y los cedros del Líbano, diciendo: Desde que tu perecistes no ha subido cortador contra nosotros" cierro comillas, fin de la cita. Este segmento se encuentra en el libro de Isaías versículos del 7 al 8 del capítulo 14, efectivamente eso debemos preguntarnos ¿Cuándo habremos vencido la inseguridad? ¿Cuándo podremos decir el malvado ha perecido? O acaso decir que el leñador ha sido despojado del hacha con la que hería al árbol de la paz social de toda la nación. Estas cosas nos inspiran en el equipo del Centro de Investigación Científica por eso nos atrevemos a pensar diferente no yendo por el camino ancho y oscuro sino por otros nuevos que también tienen riesgos y peligros por ello cuidamos este proyecto editorial para que sea un instrumento esclarecedor, propicie justicia, plantee verdad y sobre todo incline a los grandes para que escuchen las aspiraciones de los pequeños y también trate con astucia a los hacedores de maldad.

En esta oportunidad me complace anunciar varios éxitos cosechados en este número de la revista científica "Policía y Seguridad Pública", el quinto en este caso dedicado a la temática estratégica "Seguridad Privada y Tráfico de Armas", esfuerzo del que me es imperativo destacar los siguientes aspectos:

1. Constituye el volumen que ha incorporado mayor cantidad de investigaciones científicas y estudios estratégicos, ocho en total. Así también la mayor cantidad de recensiones y sinopsis de cine, libros y documentos web que están relacionados con la temática; incrementando en su conjunto la cantidad de páginas efectivas cuya presencia en cada número ronda entre setenta al ochenta por ciento del total del material, sobrepasando el sesenta por ciento mínimo que se exige internacionalmente como un parámetro de gestión científica e editorial.

2. Estos estudios e investigaciones son inéditas, novedosas y originales lo que da cumplimiento a nuestra política y mística de no aceptar trabajos con publicaciones previas que impactan negativamente el nivel y posicionamiento internacional de la revista, además se trata de investigaciones alineadas a los requerimientos de nuestra agenda de investigación institucional y a los programas de investigación concebidos por el Centro de Investigación Científica; es en este sentido que se alinean con las convocatorias y las fichas de estudio específicas que se consensan con actores y especialistas potenciales. 

número de la revista "Policía y Seguridad Pública"

3. Este quinto número se erige como el primer esfuerzo pionero dedicado a la temática de Seguridad Privada en El Salvador, lo preexistente son artículos dispersos que se cuentan con los dedos de las manos; uno de ellos publicado en el país por segunda ocasión, mientras que otros esfuerzos se encuentran escasamente divulgados entre el funcionariado y la comunidad académica en el país.

4. Esta edición incluye estudios e investigaciones sobre aristas de análisis no exploradas con anterioridad tales como: el uso de tecnología para el control de empleados, las jornadas laborales prolongadas a las que se enfrentan los guardias de seguridad privada, la inversión estatal en seguridad privada, los riesgos psicosociales presentes en esta esfera de la actividad empresarial entre otros.

5. Es necesario destacar tres aportes recibidos en este número dos de los cuales tendrán oportunidad de conocerlos a través de las mismas palabras de sus autores, el primero concierne a la dinámica laboral al interior del mundo de las empresas de seguridad privada; un esfuerzo importante que revela las distorsiones en la relaciones entre Estado, empresas de seguridad y guardias privados como trabajadores. Esta iniciativa fue posible por la estrecha colaboración entre el Departamento de Servicios Estatales y Privados de Seguridad de la ANSP y el Centro de Investigación Científica, desde el principio creímos en este proyecto y logramos capitalizar toda la experiencia del profesorado y por ende darle forma extensa y ambiciosa a dicha iniciativa.

Así también por vez primera hemos incluido un estudio estratégico en el que se analizan técnicamente los sistemas armamentísticos y el poder de fuego de las pandillas; trabajo realizado por un especialista de la historia militar y conflictos armados, un documento de obligada lectura para todos los mandos y cuadros intermedios de la Policía Nacional Civil y la Fuerza Armada. Por su parte el tercer esfuerzo constituye la primera entrega de un ambicioso proyecto de investigación que desarrollará el Centro de Investigación Científica y que está referido a la inversión estatal y la seguridad privada.

6. Este número cuenta con tres nuevas indizaciones internacionales, que las podrán encontrar en la chapeta de la revista y que la posicionan globalmente y la refuerzan como publicación de referencia entre las comunidades académicas y el funcionariado de seguridad en los distintos países. Una de ellas VLEX, una Biblioteca Virtual especializada en Criminología y en Ciencias Jurídicas y E. Revistas del Consejo de Investigaciones Científicas de España y encontrándose también en proceso de alta en Dialnet otra base de datos académica que pertenece a la Universidad de La Rioja también de España.

7. También se logró en este número diversificar las especialidades de los autores, también las filiaciones académicas e institucionales de los evaluadores nacionales e internacionales entre estos destacan las participaciones académicas de gente de instituciones tan variadas como la Universidad de Postdam (Alemania); la ONG Casa Común (México); Universidad de Barcelona, Centro Regional de la Naciones Unidas para la Paz y el Desarme (Perú); Mossos de Squadra que es un Cuerpo de Policía de España; Centro de Estudios 
de Seguridad Ciudadana (Chile); del Programa de Investigación Aplicada en Seguridad y Operaciones (Argentina); Instituto de Ciencia,Tecnología e Innovación de la Universidad Francisco Gavidia; del Centro de Investigación de Prevención de la Violencia que tiene sede en Guatemala; de Ia National Defense University (Estados Unidos de Norte América); del Ministerio de Justicia y Seguridad Pública, Fundación Salvadoreña para el Desarrollo Económico y Social (FUSADES), Unidad de Investigación de la Facultad de Ciencias y Humanidades de la Universidad de El Salvador; Departamento de Formación Inicial de la Academia Nacional de Seguridad Pública; de la Facultad de Jurisprudencia y Ciencias Sociales también de la Universidad de El Salvador; del Centro Nacional de Investigaciones Científicas (CICES) del Ministerio de Educación; del Centro Nacional de Investigaciones en Ciencias Sociales y Humanidades (CENICSH) y también del Food Science Advisory Council, Human Health Organization con sede en New York.

8. Se incrementó la participación de profesionales de la ANSP y de otras instituciones en la elaboración de sinopsis de cine, documentos web y libros; totalizando ocho que encontrarán en una sección muy amena de la revista que se denomina "Conozca más".

9. Este número tiene conexiones importantes con los proyectos de edición futura que cubren períodos prolongados de tiempo, que van más allá de un quinquenio y todo ello sobre la base del concepto estratégico de los programas y la agenda de investigación institucional. De esta realidad se encuentran programados números dedicados a la prospectiva de seguridad que esperamos estar presentando a principios del mes de diciembre, la inteligencia estratégica y otros temas sobre pandillas y extorsiones; en el caso de los dos primeros, iniciativas que también serán pioneras en el país y porque no decirlo posiblemente en Latinoamérica; queremos consolidar un valor de uso de la investigación para los imperativos de ingeniería y reinvención de la seguridad.

Después de la descripción de estos aspectos me permito pasar al tema que nos ocupa la seguridad privada, este apartado lo he denominado algunos mitos y falta de enfoques adecuados sobre la seguridad privada en El Salvador y otros países:

1. El fenómeno de la seguridad privada está erosionando la persistencia del Estado por conservar el monopolio legítimo de la fuerza, lo cierto es que los Estados no invierten lo suficiente en seguridad pública y sí lo hacen por el contrario en forma creciente en los servicios de seguridad privada, lo anterior no es un pecado mortal sobre todo porque está ausente una política estratégica que conciba una relación clave entre el mundo de la seguridad privada y la comunidad de la seguridad pública de los Estados, para los menesteres del tratamiento de las amenazas transnacionales y otras de influencia global y local; nótese que si los Estados dieran marcha atrás en la contratación de los servicios privados de seguridad y ésta es una de las paradojas para organizar sus propios dispositivos en sus propias instalaciones públicas. Constituiría una transición riesgosa y delicada, entre estas por algunas cuestiones como las siguientes: 
a. Sobrevendría una recarga adicional general para los aparatos policiales, que ante las antiguas funciones recuperadas demandarían más plantía policial; incrementándose así la fuerza del Estado en el cuido de posiciones fijas.

b. Restaría efectividad e impactaría negativamente el desempeño policial pues absorbería fuerzas operativas que es la que se mantiene movilizada para realizar las acciones de choque contra la delincuencia; los incrementos de nuevas plantías solo complicaría los ya mermados presupuestos en el rubro.

2. Qué el fenómeno de la seguridad privada refuerza el reclutamiento de legionarios para actuar en zonas de conflictos internacionales, prevaleciendo la imagen de un guerrero privado desalmado que busca fortuna a toda costa sin que medien análisis y aproximaciones de la economía política de estas expediciones y de cómo las mismas generan expectativas también de progreso individual para quienes han acumulado experiencia militar pero que entienden muy bien que trabajar para una multinacional de la seguridad privada no tiene comparación con los incentivos económicos de la oferta de trabajo local. Que comprenden además que el desconocimiento de una lengua extranjera preferentemente el inglés, los margina de mayores ingresos aún en una expedición en un área de guerra incluso generándoles mayores riesgos ante la imposibilidad de tener control sobre un instrumento comunicativo para la interlocución; por ello para quienes trabajan sobre este punto los dilemas de confiar en soldados extranjeros se ilustran en un interesante pasaje de las escrituras que está en el libro de Samuel cito, abro comillas "Y cuando los príncipes de los filisteos pasaban revista de sus compañías de a ciento y de mil hombres, David y sus hombres iban en la retaguardia con Aquis. Y dijeron los príncipes de los filisteos: ¿Qué hacen aquí estos hebreos? Y Aquis respondió a los príncipes de los filisteos no es este el siervo de Saúl rey de Israel, que ha estado conmigo por días y años, y no he hallado falta en él desde el día que se pasó a mí hasta hoy. Entonces los príncipes de los filisteos se enojaron contra él, y le dijeron: Despide a este hombre para que se vuelva al lugar que le señalaste, y no venga contra nosotros a la batalla, no sea que en la batalla se nos vuelva enemigo; porque ¿Con qué cosa volvería mejor a la gracia de su señor que con las cabezas de estos hombres?"(Samuel 29:1 - 4). Acá se nos muestra sobre los dilemas de confiar en legionarios o soldados extranjeros que son otros de los temas de los cuales también no hay investigación, todos tienen una causa individual desde la necesidad que les favorezca la fortuna hasta el interés individual por mejorar; pero arriesgando la vida misma, este episodio nos muestra también el contexto del futuro rey de Israel huyendo del rey Saúl y sirviendo a un ejército extranjero en este caso una nación acérrima enemiga del pueblo hebreo.

3. Que los desafíos de la seguridad en general supone esfuerzos de 365 días y 24 horas y que plantea dilemas claves expresados en el hecho que incrementa la oferta de trabajo para propiciar relevos ordenados entre los guardias de seguridad privada, que repercutirían positivamente en la efectividad de los mismos reduciendo la falta de identificación y compromiso. O se avanza a la robotización de los procesos, invirtiéndose más en tecnología inteligente; a fin de cuentas el empleador de seguridad privada no debe olvidar que el guardia se somete a jornadas prolongadas y escenarios adversos, también 
tiene necesidades fisiológicas, experimenta miedo, descontento, se cansa, su capacidad de alerta se reduce entre más se le prive del sueño; así también su paciencia se erosiona y ello impacta la capacidad de resolver favorablemente situaciones límites, por todo lo anterior el fenómeno de la seguridad privada requiere de lo siguiente:

4. El desarrollo e implementación de un programa de investigación, tarea de la que ya se está ocupando el Centro de Investigación Científica; siendo fieles a nuestra mística de explorar las aristas no estudiadas, y al imperativo de buscar caminos que no se aten al convencionalismo de hacer las cosas.

5. Requerirá un acercamiento al mundo de las empresas de seguridad privada, las gremiales privadas y las organizaciones públicas, todas deben entender que no son lo que piensan que son sino lo que piensan los de afuera de ellas, por eso esta exhortación es hacia las sinergias que deben basarse en el mutuo descubrimiento, en la creatividad para cooperar y en la innovación para completar un esfuerzo común y vital hacia la seguridad pública y estabilidad que demandaría nuestro país.

6. La existencia de un programa de investigación sobre este rubro servirá para el análisis de la justa dimensión de este fenómeno y para prevenir posturas preconcebidas o ideologizaciones, muchas de ellas instaladas en el mundo académico que imposibilitan la creación de constructos adecuados para su abordaje.

Deseo finalmente expresar mis agradecimientos a Karlen Moreno, Alejandra Gutiérrez, Manuel Olivar, Carlos Escobar, Ana Jeannette García, Yesenia Delgado, Mariella Vega Gutiérrez; quienes durante mi ausencia se movilizaron y tomaron distintas iniciativas para resolver y hacer práctico lo difícil y tener siempre alternativas cuando los primeros planes se complicaron; así también extiendo mis agradecimientos a Augusto López Ramírez quien fungió como coordinador interino durante varias semanas, esto es una garantía que este proyecto no descansa necesariamente en determinadas personas; en definitiva la inseguridad y la violencia sólo pueden superarse esforzándonos y siendo valientes, tal como se le ordenó a Josué sucesor de Moisés, que cito a continuación, abro comillas: "Esfuérzate y se valiente; porque tú repartirás a este pueblo por heredad la tierra de la cual juré a sus padres que le daría a ellos" (Josué 1:6); a eso estamos llamados, a dar en heredad la paz y garantizarla para nuestros hijos, negándonos a nosotros mismos y desechando el leviatán del miedo y la resignación.

Muchas gracias.

Juan Carlos Morales Peña Coordinador Principal del Centro de Investigación Científica Editor Jefe de la Revista "Policía y Seguridad Pública" Academia Nacional de Seguridad Pública Julio 09 de 2014 